\title{
Can the humped animal's knee conceal its name? Commentary on: "The roles of shared vs. distinctive conceptual features in lexical access"
}

\author{
Maria Montefinese $^{1 * \dagger}$ and David Vinson ${ }^{2 \dagger}$ \\ ${ }^{1}$ Department of Neuroscience, University of Padova, Padova, Italy, ${ }^{2}$ Department of Experimental Psychology, Institute for \\ Multimodal Communication, University College London, London, UK
}

Keywords: shared feature, distinctive feature, picture-word interference, lexical access, lexical selection by competition, response exclusion

\section{A commentary on}

The roles of shared vs. distinctive conceptual features in lexical access by Vieth, H., McMahon, K., and De Zubicaray, G. (2014). Front. Psychol. 5:1014. doi: 10.3389/fpsyg.2014.01014

OPEN ACCESS

Edited by:

Albert Costa

University Pompeu Fabra, Spain

Reviewed by:

Kevin Matthew Sailor

Lehman College, USA

*Correspondence:

Maria Montefinese,

maria.montefinese@gmail.com

${ }^{t}$ These authors have contributed

equally to this work.

Specialty section:

This article was submitted to

Language Sciences, a section of the

journal Frontiers in Psychology

Received: 04 February 2015

Accepted: 24 March 2015

Published: 10 April 2015

Citation:

Montefinese $M$ and Vinson D (2015)

Can the humped animal's knee conceal its name? Commentary on:

"The roles of shared vs. distinctive conceptual features in lexical access".

Front. Psychol. 6:418

doi: 10.3389/fpsyg.2015.00418
The representation of meaning is a pivotal topic for theories of language processing. A prevalent view is based on semantic features, considering conceptual representations as distributed patterns of activity across sets of features related to different aspects of knowledge and experience (e.g., Rosch and Mervis, 1975; Vigliocco et al., 2004; Cree et al., 2006). These features can vary in their relative salience to a concept's meaning and co-occur to various degrees across concepts. For example, distinctive features occur in few concepts and allow people to distinguish very similar concepts (Grondin et al., 2009), while shared features occur across many concepts thus indicating similarity among them (Montefinese et al., 2014a). Existing studies yield conflicting results about the relevance of featural characteristics (Montefinese et al., 2014b), leaving it unclear what theoretical interpretations can be drawn.

Vieth et al. (2014) recently sought to clarify the role of feature distinctiveness in a picture-word interference (PWI) task. In Experiment 1, they employed categorically-related distractor-target pairs matched for semantic similarity, while manipulating distinctiveness of the distractor feature. Experiments 2 and 3 employed part-whole distractor pairs while manipulating distinctiveness and visibility of the distractor feature in the target picture. Distinctiveness had an extremely constrained effect: non-distinctive feature distractors slowed target naming, but only at an SOA of $-150 \mathrm{~ms}$ and only when they were visible in the picture (Experiment 3 ). The authors conclude that semantic interference in the PWI paradigm is due to conceptual feature overlap and thus consistent with lexical selection by competition (Roelofs, 1992) rather than the response exclusion hypothesis introduced by Mahon et al. (2007).Unfortunately, these conclusions are undermined by lack of a crucial statistical interaction to motivate follow-up testing, poor control of semantic measures, and an inadequate account of the role distinctiveness would play in lexical retrieval.

Vieth et al. found one effect of distinctiveness: in Experiment 3, "non-distinctive part-whole target relations showed picture naming latencies significantly at $-150 \mathrm{~ms}$ SOA compared to their matched unrelated pairings" (p. 9). However, such conclusions are not warranted by the evidence provided. The authors drew conclusions from partial interactions without a significant 
TABLE 1 | Materials from Vieth et al. (2014) Experiment 2 and 3.

\begin{tabular}{|c|c|c|c|c|c|c|}
\hline \multirow[b]{2}{*}{ Target picture } & \multicolumn{2}{|c|}{ Distinctive } & \multicolumn{2}{|c|}{ Non-distinctive (Exp2) } & \multicolumn{2}{|c|}{ Non-distinctive (Exp3) } \\
\hline & Feature & Dominance & Feature & Dominance & Feature & Dominance \\
\hline BAT & Fangs & 7 & Stomach & NA & & \\
\hline BED & Springs & 7 & Foam & $N A^{a}$ & & \\
\hline BRA & Hook & 9 & Cloth & 5 & & \\
\hline CAMEL & Hump & 25 & Knee & $\mathrm{NA}$ & & \\
\hline $\mathrm{CHURCH}$ & Altar & 8 & Seat & 11 & & \\
\hline CLOCK & Face & 7 & Spindle & $N A^{b}$ & Glass & $N A^{d}$ \\
\hline COTTAGE & Fireplace & 6 & Floor & NA & & \\
\hline cow & Udder & 8 & Liver & NA & Skin & NA \\
\hline CROCODILE & Jaws & 7 & Heart & NA & Scales & 8 \\
\hline DISHWASHER & Rack & 13 & Hose & NA & Latch & NA \\
\hline DUCK & Bill & 14 & Eye & NA & & \\
\hline ELEPHANT & Trunk & 23 & Teeth & $N A^{C}$ & Toe & NA \\
\hline ELEVATOR & Cable & 9 & Ceiling & NA & & \\
\hline GOAT & Beard & 14 & Tail & 6 & & \\
\hline GRENADE & Pin & 23 & Lever & NA & & \\
\hline GUITAR & Hole & 8 & Fret & $\mathrm{NA}$ & & \\
\hline LAMP & Switch & 10 & Cord & 5 & & \\
\hline MISSILE & Warhead & 6 & Engine & NA & Fin & NA \\
\hline MIXER & Bowl & 5 & Plug & NA & & \\
\hline MOUSE & Ball & 9 & Sensor & $\mathrm{NA}$ & Button & 9 \\
\hline PEACH & Stone & 6 & Stem & NA & & \\
\hline$P I G$ & Snout & 12 & Tongue & NA & Hair & NA \\
\hline PINEAPPLE & Core & 6 & Stone & NA & Leaf & 7 \\
\hline VULTURE & Talons & 6 & Bone & NA & Wings & 8 \\
\hline
\end{tabular}

The two rightmost columns indicate the non-distinctive features used in Experiment 3 only when they differed from those used in Experiment 2. "NA": a feature did not appear in McRae et al. (2005) norms, and thus had a dominance of 4 or less in that set.

aMost similar feature in McRae et al.'s norms: "has a mattress" (dominance $=18$ ).

bMost similar feature in McRae et al.'s norms: "has hands" (dominance = 18).

"Most similar feature in McRae et al.'s norms: "has tusks" (dominance = 14).

"Most similar feature in McRae et al. 's norms: "has a face" (dominance = 7).

higher-order interaction. However, this is a common problem in studies employing factorial ANOVA (see Nieuwenhuis et al., 2011), and is likely to inflate the likelihood of Type I error particularly in repeated-measures ANOVA, which is anticonservative for designs including crossed random effects by-participants and by-items (Quené and van den Bergh, 2008). We therefore wonder whether the most appropriate conclusion from Experiment 3 is that, as in Experiments 1 and 2, feature distinctiveness does not affect the degree of interference in PWI.

Moreover, although the authors made careful efforts to match lexical variables between conditions, some crucial semantic variables remain uncontrolled. For example, there are substantial differences in dominance of the distinctive and non-distinctive features Vieth et al. used in their experiments. Moreover, hardly any of the non-distinctive features appear in McRae et al.'s (2005) norms (Table 1), indicating that participants do not find features like "knees" of CAMELS sufficiently salient to report them. Classic feature-verification studies using very similar item sets (e.g., Conrad, 1972; Glass et al., 1974) suggest that distinctiveness effects are substantially reduced or eliminated by taking dominance into account; and more recent work by O'Connor et al. (2009) suggests that non-distinctive features are much more highly associated with superordinate terms (e.g., "animal" or "mammal") than the basic-level terms employed by Vieth et al. Therefore, if dominance is a measure of a feature's semantic proximity to the target concept label (and thus its level of competition for lexical selection under selection-bycompetition accounts), the activation of target concepts by nondistinctive features would depend on their dominance. Features that are salient for multiple concepts would activate competing concepts and interfere with their naming, while those that are not salient for any concept would not. Examples of these two types of non-distinctive features are, respectively, "bone" and "skin," which were listed for none and 16 of the 541 concepts of McRae et al.'s norms. In brief, distinctiveness alone would not explain how strongly a feature can activate one or more target concepts. But let us set aside statistical and methodological concerns about Experiment 3 and assume that the effect they describe is real interference for visible non-distinctive part distractors at $-150 \mathrm{~ms}$ SOA only. The authors do not adequately describe the processes that might have caused this temporallyselective effect, instead discussing the three-way interaction (SOA 
$\times$ part-relation $\times$ distinctiveness) as if it was the two-way interaction (part-relation $\times$ distinctiveness, which is far from statistical significance). Moreover, the proposed mechanism by which this effect would occur under selection-by-competition is discussed as spreading activation from a target concept to a related distractor (a visible, non-distinctive feature in this case). If this is the mechanism underlying this effect, one should expect no difference between $-150 \mathrm{~ms}$ and $0 \mathrm{~ms}$ SOA: activation of target concept cannot begin before it has appeared. If anything, spread of activation in the other direction [i.e., from feature to its associated concept(s)] should initially drive this effect at $-150 \mathrm{~ms}$ SOA. And finally, if this effect occurs only when the feature is visible (for counter evidence, see Sailor and Brooks, 2014), we wondered whether there may be a contribution of level of specificity (akin to the basic-level/superordinate naming tasks reviewed by Mahon et al., 2007): might the visibility of the distractor feature permit further activation of its name as a potentially plausible alternative to the basic-level target name?

\section{References}

Conrad, C. (1972). Cognitive economy in semantic memory. J. Exp. Psychol. 92, 149-154. doi: 10.1037/h0032072

Cree, G. S., McNorgan, C., and McRae, K. (2006). Distinctive features hold a privileged status in the computation of word meaning: implications for theories of semantic memory. J. Exp. Psychol. Learn. Mem. Cogn. 32, 643-658. doi: 10.1037/0278-7393.32.4.643

Glass, A. L., Holyoak, K. J., and O'Dell, C. (1974). Production frequency and the verification of quantified statements. J. Verbal Learning Verbal Behav. 13, 237-254. doi: 10.1016/S0022-5371(74)80061-7

Grondin, R., Lupker, S., and McRae, K. (2009). Shared features dominate semantic richness effects for concrete concepts. J. Mem. Lang. 60, 1-19. doi: 10.1016/j.jml.2008.09.001

Mahon, B., Costa, A., Peterson, R., Vargas, K., and Caramazza, A. (2007). Lexicalselection is not by competition: a reinterpretation of semantic interference andfacilitation effects in the picture-word interference paradigm. J. Exp. Psychol. Learn. Mem. Cogn. 33, 503-535. doi: 10.1037/0278-7393.33.3.503

McRae, K., Cree, G. S., Seidenberg, M. S., and McNorgan, C. (2005). Semantic feature production norms for a large set of living and nonliving things. Behav. Res. Methods 37, 547-559. doi: 10.3758/BF03192726

Montefinese, M., Ambrosini, E., Fairfield, B., and Mammarella, N. (2014b). Semantic significance: a new measure of feature salience. Mem. Cognit. 42, 355-369. doi: 10.3758/s13421-013-0365-y

Montefinese, M., Zannino, G. D., and Ambrosini, E. (2014a). Semantic similarity between old and new items produces false alarms in recognition memory. Psychol. Res. 1-10. doi: 10.1007/s00426-014-0615-z. [Epub ahead of print].

Nieuwenhuis, S., Forstmann, B. U., and Wagenmakers, E. J. (2011). Erroneous analyses of interactions in neuroscience: a problem of significance. Nat. Neurosci. 14, 1105-1107. doi: 10.1038/nn.2886

O'Connor, C. M., Cree, G. S., and McRae, K. (2009). Conceptual hierarchies in a flat attractor network: dynamics of learning and computations. Cogn. Sci. 33, 665-708. doi: 10.1111/j.1551-6709.2009.01024.x
Although we appreciate Vieth et al.'s effort to advance our theoretical understanding of lexical retrieval processes through careful manipulation of feature properties, we cannot draw conclusions about the locus of semantic effects in PWI from the present study. Ultimately, a crucial problem is that the details of conceptual representation remain underspecified, and may have major consequences, for example, in predicting whether a feature label should compete with a basic level label (see Vinson et al., 2014). Incorporating explicit models of semantic similarity may offer a way forward in testing current theories of lexical retrieval.

\section{Acknowledgments}

DV was supported by UK Economic and Social Research Council (grant ES/K001337/1).

Quené, H., and van den Bergh, H. (2008). Examples of mixed-effects modeling with crossed random effects and with binomial data. J. Mem. Lang. 59, 413-425. doi: 10.1016/j.jml.2008.02.002

Roelofs, A. (1992). A spreading-activation theory of lemma retrieval in speaking. Cognition 42, 107-142. doi: 10.1016/0010-0277(92)90041-F

Rosch, E., and Mervis, C. B. (1975). Family resemblances: studies in the internal structure of categories. Cogn. Psychol. 7, 573-605. doi: 10.1016/00100285(75)90024-9

Sailor, K., and Brooks, P. J. (2014). Do part-whole relations produce facilitation in the picture-word interference task? Q. J. Exp. Psychol. (Hove) 67, 1768-1785. doi: 10.1080/17470218.2013.870589

Vieth, H., McMahon, K., and de Zubicaray, G. (2014). The roles of shared vs. distinctive conceptual features in lexical access. Front. Psychol. 5:1014. doi: 10.3389/fpsyg.2014.01014

Vigliocco, G., Vinson, D. P., Lewis, W., and Garrett, M. F. (2004). Representing themeanings of object and action words: the featural and unitary semantic space hypothesis. Cogn. Psychol. 48, 422-488. doi: 10.1016/j.cogpsych.2003. 09.001

Vinson, D., Andrews, M., and Vigliocco, G. (2014). “Giving words meaning: why better models of semantics are needed in language production research," in Oxford Handbook of Language Production, eds V. Ferreira, M. Goldrick, and M. Miozzo (Oxford, UK: Oxford University Press), 134-151.

Conflict of Interest Statement: The authors declare that the research was conducted in the absence of any commercial or financial relationships that could be construed as a potential conflict of interest.

Copyright (c) 2015 Montefinese and Vinson. This is an open-access article distributed under the terms of the Creative Commons Attribution License (CC BY). The use, distribution or reproduction in other forums is permitted, provided the original author(s) or licensor are credited and that the original publication in this journal is cited, in accordance with accepted academic practice. No use, distribution or reproduction is permitted which does not comply with these terms. 